\title{
Treatment of Nosocomial Pneumonia: An Experience with Meropenem
}

\author{
Sigrid S. Santos, Flavia R Machado, \\ Carlos R. V. Kiffer and Antonio A. Barone
}

\author{
Infectious Diseases Department, School of \\ Medicine, University of São Paulo, SP, Brazil
}

\begin{abstract}
This study aimed at evaluating the efficacy and safety of meropenem as first choice treatment for nosocomial pneumonia (NP) in intensive care units (ICU) in Hospital das Clínicas (HC) University of São Paulo; a hospital with high incidence of antimicrobial resistance. Prospective, open, and non-comparative trial with meropenem were done in patients with ventilator-associated or aspiration NP in 2 ICUs at HC - University of São Paulo. Etiologic investigation was done through bronchoalveolar lavage and blood cultures prior to study entry. Twenty-five (25) critically ill patients with NP were enrolled (mean age 40 years). Ventilator-acquired pneumonia was responsible for $76 \%$ of cases and aspiration NP for $24 \%$. Specific etiologic agents were identified and considered to be clinically and temporally responsible for NPin 11 (44\%) patients. A. baumanii was responsible for 6 cases (55\%), P. aeruginosa for $3(27 \%)$, and $S$. aureus for $2(18 \%)$. At completion of treatment, 19 patients $(\mathbf{7 6} \%)$ showed either cure $(48 \%)$ or improvement $(28 \%)$ after use of meropenem therapy. Mortality was $12 \%$ at the end of therapy (8\% after excluding 1 non-evaluable patient). After 4 to 6 weeks of follow-up, 12 (48\%) patients had improved or been totally cured, and overall mortality was $24 \%$. Clinical complications were observed in 11 patients (44\%), with none of them definitely related to the study drug. Meropenem as monotherapy was effective and well-tolerated in most NP patients in our ICU. The low mortality rate in this study might have been due to first choice use of this drug. Controlled, drug comparative clinical trials are needed to support this preliminary observation.
\end{abstract}

Key Words: Meropenem, nosocomial pneumonia, intensive care unit.

It is well known that multi-resistant bacterial strains are increasingly prevalent in hospital environments. Bacterial resistance is an important problem to be faced especially by practitioners in Intensive Care Units (ICUs) worldwide.

Increasing, and sometimes inappropriate, antibiotic therapy has resulted in a higher incidence of resistant bacteria that may be difficult to treat. This, coupled with a rising number of debilitated patients, means that the need for correct use of antibiotics and for careful clinical and microbiological studies has never been greater.

Received on 22 December 2000; revised 13 March 2001.

Address for correspondence: Dr. Carlos R. V. Kiffer. Alameda dos Guaicanãs 984 - Planalto Paulista - São Paulo/SP - Brazil; Zip code: 04064-031.E-mail: kiffer@uninet.com.br

Financial Support: AstraZeneca do Brasil Ltda.

The Brazilian Journal of Infectious Diseases 2001;5(3):124-129 (C) 2001 by The Brazilian Journal of Infectious Diseases and Contexto Publishing. All rights reserved. $1413-8670$
The development of new drugs may also be a priority in these circumstances. Research has been done with many different classes of antibiotics and the carbapenems, which are broad-spectrum $\beta$-lactam antibiotics, are among those of greatest interest.

Meropenem is the first of a new class of dehydropeptidase-stable carbapenem antibiotics [1]. It is highly active against a wide spectrum of pathogenic bacteria [2], including Gram positive and Gram negative microorganisms and anaerobes. Despite its lack of activity against Staphylococcus $s p$ resistant to methicillin, Enterococcus faecium, Enterococcus faecalis, Streptococcus pneumoniae with high level resistance to penicillin, and Stenotrophomonas maltophilia; meropenem has been shown to be effective against strains of Enterobacteriaceae, Pseudomonas spp, and Acinetobacter spp resistant to third generation cephalosporins, quinolones and aminoglycosides [3]. 
Meropenem has been shown to be effective in treating a range of infections in experimental animal models [4], and has shown good safety and efficacy in clinical trials in patients with nosocomial infections [18, 19], including those caused by multi-resistant bacterial strains $[5,17]$.

Pneumonia is the second most common nosocomial infection [4], accounting for $13 \%$ to $18 \%$ of all hospital infections [6]. Nosocomial pneumonia (NP) occurs in $5 \%$ to $10 \%$ of hospital admissions $[3,7,13]$ and this rate increases 6 to 20 times in mechanically ventilated patients [20]. The crude mortality rates for hospital pneumonia range from $20 \%$ to $70 \%$ [2, 6, 13], probably due to the severity of underlying diseases in the population studied. In contrast, attributable mortality due to pneumonia has been estimated as $30 \%$ to $50 \%$ $[6,11,13]$.

Clinical diagnosis of NP is based on the presence of a new radiological pulmonary infiltrate [10] in a patient with 2 of the following criteria: purulent sputum, fever or hypothermia, leukocytosis, or leukopenia [13]. For mechanically ventilated patients, clinical criteria for the diagnosis of pneumonia lack specificity, thus leading to controversy over the benefits and risks of using more specific and invasive diagnostic methods [6, 13].

Etiological agents can be isolated by bronchoalveolar lavage (BAL) and/or protected specimen brush (PSB) with $85 \%$ to $100 \%$ sensitivity and $95 \%$ to $100 \%$ specificity [6]. As bronchoscopy is an invasive technique and not always available, nonbronchoscopic or "blind" BAL appears to provide reliable results [15]. Blood cultures can provide a specific diagnosis in patients with bacteremia. Gram's stain or culture of pleural fluid are specific, but can only be performed in a small number of patients $[6,13]$.

The main causative agents in NP are aerobic Gramnegative bacilli (Enterobacteriaceae, Pseudomonas spp, Acinetobacter spp). They have been implicated in $20 \%$ to $60 \%$ of reported cases $[6,13]$. Staphylococcus aureus is responsible for $20 \%$ to $40 \%$ of cases, and anaerobes in $0 \%$ to $35 \%$ of cases. Community agents like Streptococcus pneumoniae and Haemophilus influenzae are generally involved in early onset (<5days) bacterial pneumonia [6, 7, 13].
This study sought to evaluate the efficacy and safety of meropenem as the first choice treatment for respirator-associated and/or aspiration nosocomial pneumonia in the ICU at Hospital das Clínicas University of São Paulo; a major tertiary hospital with a high prevalence of antimicrobial resistance.

Secondary aims were to evaluate bacteriological efficacy of meropenem and to assess the safety and tolerance of meropenem, as measured by the incidence of adverse events and the effects on appropriate hematological and biochemical variables.

\section{Materials and Methods}

This was a prospective, open, non-comparative trial with meropenem in ventilator-associated or aspiration nosocomial pneumonia. Twenty-five (25) patients were recruited at 2 intensive care units at the Hospital das Clínicas - University of São Paulo between April, 1997, and September, 1998.

Patients aged 18 years or older were included. Written and/or witnessed informed consent to participate in the trial was taken prior to initiating the study. Comatose patients were included only after the informed consent was obtained from a legally responsible relative. Patients eligible for inclusion were necessarily hospitalized with the presence of new radiological pulmonary infiltrate, purulent sputum, and signs of sepsis, thus requiring a parenteral antibiotic. Clinical categories included were aspiration pneumonia and ventilator-associated pneumonia according to classifications in the Guidelines for Prevention of Nosocomial Pneumonia [7]. Patients with previous broad spectrum antibiotic therapy were included only if bacterial isolates were resistant to them and susceptible to carbapenems. If multiple pathogens were present at entry, at least 1 isolate must have been susceptible to the study drug. Patients using narrow spectrum penicillin to community acquired infections, anti-tuberculous drug, or anti-toxoplasmic therapy were also included.

Patients were excluded from the study if any of the following criteria was found: pregnancy or breast feeding; hypersensitivity to any $\beta$-lactam; another 
investigational drug given within 30 days prior to study entry; severe hepatic impairment, such as hepatic failure or hepatic coma; neutropenia (neutrophil count $<1000$ cells $/ \mathrm{mm}^{3}$ ); cystic fibrosis; previous trial entry; patient unlikely to complete at least 48 hours of trial drug treatment; previous treatment with a potentially effective antibiotic within the last 24 hours prior to treatment, unless the microorganism was shown to be resistant or was still present and susceptible to carbapenems.

Meropenem was given intravenously in bolus at a dose of $1 \mathrm{~g}$ every 8 hours, due to the high prevalence of resistant microorganisms in the study environment and, thus, the high possibility of $P$. aeruginosa and Acinetobacter sp infections. Dose adjustments were made in patients with impaired renal function, according to prescribing information. Duration of treatment depended on the clinical and bacteriological presentation, however a treatment duration period of 5 to 21 days was established for all patients.

Etiological investigation was done through bronchoalveolar lavage (bronchoscopic or "blind") and blood cultures prior to study entry. Pleural fluid culture was obtained and considered diagnostic when indicated. Subsequent per- and post-treatment cultures were done according to clinical needs.

Clinical assessments were done pre-, per- and posttreatment period, including a general physical examination, laboratory and chest radiographic evaluations. Follow-up evaluations were done in most patients at 4 to 6 weeks after the completion of treatment.

Laboratory blood evaluation included hemoglobin, hematocrit, WBC, platelet count, serum creatinine, total bilirubin, albumin, alkaline phosphatase and hepatic enzymes (SGOT and SGPT).

After clinical, microbiological, laboratory and chest radiographic assessments, patients were classified into 5 different categories according the overall response at the end of treatment and follow-up evaluation: cure; improvement; failure; relapse; and not evaluable.

Data analysis was descriptive, with the results resumed in tables of frequency. The numeric variables were presented as mean, variance, and standard deviation.

\section{Results}

The study was conducted in 2 ICUs at the HC University of São Paulo, between April, 1997, and September, 1998. Twenty-five (25) critically ill patients with nosocomial pneumonia (NP), aged 18 to 77 (mean 39.9) were enrolled. Sixteen (64\%) were male (Table 1). Ventilator-acquired NP was responsible for $76 \%$ of cases and aspiration NP occurred in $24 \%$ of patients.

Underlying diseases were: tetanus (8); AIDS plus opportunistic infection (6); leptospirosis (4); neurological diseases (3); measles plus encephalitis (1); severe malaria (1); rheumatic disease, with longterm steroids (1); staphylococcal sepsis (1) (see Table 1). Eighteen (72\%) presented some degree of conscious impairment.

Eleven patients (44\%) were using narrow spectrum antibiotics for underlying diseases at the time of inclusion: 8 were receiving penicillin $\mathrm{G}$ for tetanus (5), or leptospirosis (3); 3 were taking oxacillin to treat tetanus focus; and 2 were being treated for tuberculous or toxoplasmic CNS infections. Five patients (20\%) were using another broad spectrum antibiotic but the microorganism was shown to be resistant or still present at the time of inclusion.

Etiological agents were isolated in 14 patients (56\%), though only 11 (44\%) were considered clinically and temporally responsible for the NP. A. baumanii was the etiological agent in 6 cases $(54.5 \%)$, with an $83.3 \%$ rate of sensitivity to meropenem. $P$. aeruginosa was the etiological agent in 3 cases $(27.3 \%)$, though the susceptibility was tested in only 1 isolate. S. aureus was the etiological agent in 2 cases (18.2\%), 1 case susceptible to meropenem.

Twelve patients developed infection at a new site during meropenem therapy, requiring the addition of another drug as follows: 8 received vancomycin $(6 S$. aureus bacteremia, 1 E. faecalis bacteremia, and 1 empirical); 5 (20\%) received amphotericin B preceded or not by fluconazole for Candida sp urinary infections (4) or abdominal sepsis (1); 1 (4\%) received gentamicin for E. faecalis bacteremia.

At the completion of treatment, 19 patients (76\%) showed cure $(48 \%)$ or improvement $(28 \%)$ with meropenem therapy. Mortality was $12 \%$ at the end of 
Table 1. Outcome of nosocomial pneumonia treated with meropenem according to age, underlying disease, and etiologic agent

\begin{tabular}{|c|c|c|c|c|c|c|}
\hline $\begin{array}{l}\text { Patient } \\
\text { number }\end{array}$ & Age & $\begin{array}{l}\text { Underlying } \\
\text { disease }\end{array}$ & $\begin{array}{l}\text { Pneumonia } \\
\text { etiology }\end{array}$ & $\begin{array}{l}\text { Adverse } \\
\text { event }\end{array}$ & $\begin{array}{l}\text { Endof } \\
\text { treatment }\end{array}$ & $\begin{array}{l}\text { Follow-up } \\
4 \text { to } 6 \text { wks }\end{array}$ \\
\hline 1 & 48 & S. aureus sepsis & $\begin{array}{l}\text { A. baumanii } \\
\text { S. aureus }\end{array}$ & $\begin{array}{l}\text { Hypotension } \\
\text { and coronary } \\
\text { spasm, hypercalemia }\end{array}$ & Improvement & Death $* *$ \\
\hline 2 & 59 & $\begin{array}{l}\text { Neurological } \\
\text { disease }\end{array}$ & $\begin{array}{l}\text { E. cloacae } \\
\text { A. baumanii }\end{array}$ & & Cure & $\begin{array}{l}\text { Cure } \\
\text { Relapse }\end{array}$ \\
\hline 3 & 23 & Tetanus & P. aeruginosa & & Cure & Cure \\
\hline 4 & 28 & Leptospirosis & Not isolated & $\begin{array}{l}\text { Cutaneous rash, } \\
\text { seizures }\end{array}$ & Cure & Cure \\
\hline 5 & 38 & Severe malaria & Not isolated & Gastritis & Cure & Cure \\
\hline 6 & 37 & AIDS and sepsis & S. aureus & & Cure & Not available \\
\hline 7 & 22 & $\begin{array}{l}\text { Measles } \\
\text { encephalitis }\end{array}$ & Not isolated & & Cure & Cure \\
\hline 8 & 50 & $\begin{array}{l}\text { AIDS and } \\
\text { hepatocellular } \\
\text { carcinoma }\end{array}$ & Not isolated & & Cure & Death $* *$ \\
\hline 9 & 56 & $\begin{array}{l}\text { AIDS and } \\
\text { cerebral } \\
\text { toxoplasmosis }\end{array}$ & Not isolated & $\begin{array}{l}\text { Adrenal failure } \\
\text { and shock }\end{array}$ & Death A A & Death \\
\hline 10 & 26 & $\begin{array}{l}\text { Neurological } \\
\text { disease }\end{array}$ & Not isolated & & Improvement & Death $* *$ \\
\hline 11 & 36 & Leptospirosis & Not isolated & $\begin{array}{l}\text { Liver enzyme } \\
\text { increase }\end{array}$ & Cure & Cure \\
\hline 12 & 42 & Tetanus & $\begin{array}{l}\text { A. baumanii } \\
\text { P. aeruginosa }\end{array}$ & & Failure & Failure \\
\hline 13 & 44 & Tetanus & Not isolated & & Cure & Cure \\
\hline 14 & 48 & Tetanus & $\begin{array}{l}\text { S. coagulase - } \\
\text { A. baumanii }\end{array}$ & & Failure & Failure \\
\hline 15 & 45 & $\begin{array}{l}\text { AIDS and } \\
\text { cerebral } \\
\text { toxoplasmosis }\end{array}$ & A. baumanii & $\begin{array}{l}\text { Pulmonary } \\
\text { embolism }\end{array}$ & $\begin{array}{l}\text { Death ** } \\
<12 \mathrm{~h}\end{array}$ & Death $* *$ \\
\hline 16 & 39 & Tetanus & Not isolated & & Improvement & $\begin{array}{l}\text { Cure } \\
\text { Relapse }\end{array}$ \\
\hline 17 & 46 & Tetanus & Not isolated & Anemia & Cure & Cure \\
\hline 18 & 43 & $\begin{array}{l}\text { AIDS and } \\
\text { encephalitis }\end{array}$ & Not isolated & Cutaneous rash & Improvement & Improvement \\
\hline 19 & 39 & Tetanus & Not isolated & & Cure & Cure \\
\hline 20 & 39 & Leptospirosis & Not isolated & & Cure & Cure \\
\hline 21 & 40 & $\begin{array}{l}\text { AIDS and } \\
\text { renal failure }\end{array}$ & P. aeruginosa & & Improvement & Death $A$ \\
\hline 22 & 31 & Rheumatological & $\begin{array}{l}\text { Enterobacter } \\
\text { cloacae }\end{array}$ & & Failure & Death A A \\
\hline 23 & 24 & $\begin{array}{l}\text { Neurological } \\
\text { disease }\end{array}$ & $\begin{array}{l}\text { S. coagulase - } \\
\text { A. baumanii }\end{array}$ & $\begin{array}{l}\text { Liver enzyme } \\
\text { increase }\end{array}$ & Improvement & Relapse \\
\hline 24 & 77 & Tetanus & H. influenzae & $\begin{array}{l}\text { Severe } \\
\text { hemorrhage }\end{array}$ & Death $* *$ & Death $* *$ \\
\hline 25 & 18 & Leptospirosis & Not isolated & Renal failure & Improvement & Cure \\
\hline
\end{tabular}

** Related to the underlying disease. $\wedge$ ^ Secondary to failure. 
therapy, though 1 patient died of pulmonary embolism within 12 hours of meropenem therapy. (end of therapy mortality was $8.5 \%$ after excluding this non-evaluable patient). After 4 to 6 weeks of follow-up, 12 (48\%) patients had improvement or total cure of NP, and general mortality was $24 \%$.

Although clinical complications were observed in 11 patients (44\%), none of them were definitely related to the study drug. Five patients presented severe complications (20\%): 4 were probably related to underlying disease (hypotension, coronary spasm and hypercalemiain a septic diabetic patient; shock and adrenal failure in 1 terminal AIDS patient; pulmonary embolism; hemorrhagic shock in an anticoagulated patient) and 1 secondary to infection at a new site (septic shock). Six patients (24\%) showed mild adverse events, 2 probably associated to the underlying disease, and 3 possibly related to meropenem (skin rash, seizure, and gastritis).

\section{Discussion}

Pneumonia is the second most common nosocomial infection and is associated with substantial morbidity and mortality. The majority of adult patients with hospital acquired pneumonia have severe underlying diseases, immunosuppression, depressed sensorium and/or cardiopulmonary diseases.

Preventive measures for hospital pneumonia include decreasing aspiration by the patient, preventing crosscontamination or colonization via hands of personnel, appropriate disinfection or sterilization of respiratory therapy devices, use of available vaccines to protect against particular infections, and education of hospital staff and patients [4].

Accurate diagnosis of NP is critical to avoid the inappropriate use of antibiotics and the development of antibiotic resistant bacterial populations. The main agents are the aerobic Gram-negative bacilli, Staphylococcus aureus and anaerobes [6,13]. Community agents, like Streptococcus pneumoniae and Haemophilus influenzae, can be involved $[6,7,13]$.

Hospital das Clínicas is one of the biggest university hospitals in Brazil. Due to its size, a characteristic flora composes its micro-environment; with Gram negative bacilli mostly resistant to third generation cephalosporines, aminoglycosides and quinolones; and Staphylococcus aureus mostly only sensitive to vancomycin and teicoplanin.

Meropenem is the second commercially available carbapenem with a broad anti-bacterial spectrum. It is highly potent against Enterobacteriacae, Pseudomonas spp, Acinetobacter spp, H. influenzae and anaerobic bacteria, with a fairly good potency against gram positive cocci $[8,14]$. Its known action against resistant organisms has stimulated its use for treatment of serious hospital acquired infections [5, 14, 17].

In this study, meropenem showed efficacy as first choice treatment for respirator-associated and/or aspiration nosocomial pneumonia in the ICU, with $76 \%$ clinical improvement $(48 \%$ cure, and $28 \%$ improvement). Mortality was $12 \%$ at the end of therapy and $24 \%$ after 4 to 6 weeks of follow-up. Our mortality rates were low compared to other studies $[2,6,11$, 13], especially when considering the high incidence of immunosuppression in our group.

Meropenem was shown to be safe, despite the high incidence of organ failure in this group. Adverse events were observed in 11 patients (44\%), but only 5 patients presented severe adverse events (20\%), none of them related to meropenem. Only 3 patients presented adverse events possibly related to meropenem (skin rash, seizure, and gastritis).

\section{References}

1. Bax R.P., Bastain W., Featherstone A., et al. The pharmacokinetics of meropenem in volunteers. J Antimicrob Chemother 1989;24(Suppl A):311-20.

2. Campbell G.D., Niederman M.S., Broughton W.A., et al. Hospital-acquired pneumonia in adults: Diagnosis, assessment of severity, initial antimicrobial therapy, and preventative strategies: A consensus statement. Am J Respir Crit Care Med 1996; 153:1711-25.

3. Celis R., Torres A., Gatell J.M., et al. Nosocomial pneumonia: a multivariate analysis of risk and prognosis. Chest 1988;93:318-24.

4. Centers for Disease Control and Prevention. Guidelines for prevention of Nosocomial Pneumonia. MMWR Morb Mortal Wkly Rep 1997;46(RR-1):1-79. 
5. Colardyn F., Faulkner K.L. Intravenous meropenem versus imipenem/cilastatin in the treatment of serious bacterial infections in hospitalized patients. J Antimicrob Chemother 1996;38(3): 523-37.

6. Craven D.E., Steger K.A., LaForce F.M. Pneumonia. In: Bennett, V and Brachman, PS, eds. Hospital Infections. Fourth Edition.Lippincott-Raven Publishers, Philadelphia, 1998.

7. David C.M. Pneumonia na UTI: bases para a antibioticoterapia empírica. Revista Brasileira de Terapia Intensiva 1997;10(1):4-11.

8. Edwards J.R., Turner P.J., Wannopo C., et al. In vitro antibacterial activity of SM-7338, a carbapenem antibiotic with stability to dehydropeptidase I. J Antimicrob Chemother 1989;33:215-22.

9. Edwards J.R., Willians S., Naim K. Therapeutic activity of meropenem in experimental infections. J Antimicrob Chemother 1989;24(Suppl A):279-85.

10. Johanson W.G., Pierce A.K., Sandford J.P., et al. Nosocomial respiratory infections with Gram-negative bacilli: the significance of colonization of the respiratory tract. Ann Intern Med. 1972;77:701-6.

11. Leu H.S., Kaiser D.L., Mori R.F., et al. Hospital-acquired pneumonia: attributable mortality and hospital stay. Am J Epidemiol 1986; 129:1258-67.

12. Lode H., Hamacher J., Eller J., et al. Changing role of carbapenems in the treatment of lower respiratory tract infections. Scand J Infect Dis 1991;96:17-23.

13. Luna C., Lomar A., David C., et al. Consenso Latinoamericano de pneumonias em pacientes adultos hospitalizados. Braz J Infect Dis 1999;(Suppl):1-20.

14. Martinez Lacasa J., Garau J. Papel de los carbapenemicos en el tratamiento de la infeccion nosocomial.[The role of carbapenems in the treatment of nosocomial infection]. Enferm Infecc Microbiol Clin 1997; 15(Suppl1):78-85.

15. Marquette C.H., Georges H., Wallet F., et al. Diagnostic efficiency of endotracheal aspirates with quantitative bacterial cultures in intubated patients with suspected pneumonia. Am Ver Respir Dis 1993; 148:138-44.

16. Moellering R.C., Eliopoulos G.M., Sentochnik D.E. The carbapenems: new broad-spectrum bb-lactam antibiotics. J Antimicrob Chemother 1989;24(Suppl A):1-7.

17. Mouton Y.J., Beuscart C. Empirical monotherapy with meropenem in serious bacterial infections. J Antimicrob Chemother 1995;36(Suppl A):145-56.

18. Principi N., Marchisio P. Meropenem compared with ceftazidime in the empiric treatment of acute severe infections in hospitalized children. J Chemother 1998;10(2):108-13.

19. Sieger B., Berman S.J., Geckler R.W., et al. Empiric treatment of hospital-acquired lower respiratory tract infections with meropenem or ceftazidime with tobramycin: a randomized study. Crit Care Med 1997;25(10):1663-70.
20. Torres A., Aznar R., Gatell J.M., et al. Incidence, risk and prognosis factors of nosocomial pneumonia in mechanically ventilated patients. Am Rev Respir Dis 1990; 142:523-52. 